\title{
PROMISING DIRECTION OF PERFECTION OF THE UTILIZATION COMBINE CYCLE GAS TURBINE UNITS
}

\author{
Albina I. Gabdullina ${ }^{1}$, Nikolay N.Galashov ${ }^{1,}{ }^{*}$, Svyatoslav A. Tsibulskiy ${ }^{1}$, Denis V. \\ Melnikov ${ }^{1}$, Ilya A. Asanov ${ }^{1}$, and Alexander S. Kiselev ${ }^{1}$ \\ ${ }^{1}$ Tomsk Polytechnic University, 634050, Tomsk, Russia
}

\begin{abstract}
Issues of improving the efficiency of combined cycle gas turbines (CCGT) recovery type have been presented. Efficiency gas turbine plant reaches values of $45 \%$ due to rise in temperature to a gas turbine to $1700{ }^{\circ} \mathrm{C}$. Modern technologies for improving the cooling gas turbine components and reducing the excess air ratio leads to a further increase of the efficiency by $1-2 \%$. Based on research conducted at the Tomsk Polytechnic University, it shows that the CCGT efficiency can be increased by $2-3 \%$ in the winter time due to the use of organic Rankine cycle, low-boiling substances, and air-cooled condensers (ACC). It is necessary to apply the waste heat recovery with condensation of water vapor from the flue gas, it will enhance the efficiency of the CCGT by 2-3 $\%$ to increase the efficiency of the heat recovery steam boiler (HRSB) to $10-12 \%$. Replacing electric pumps gas turbine engine (GTE) helps to reduce electricity consumption for auxiliary needs CCGT by $0.5-1.5 \%$. At the same time the heat of flue gas turbine engine may be useful used in HRSB, thus will increase the capacity and efficiency of the steam turbine.
\end{abstract}

\section{Introduction}

Combined cycle gas turbine (CCGT) unit of utilization type in the foreseeable future will be the main power generating units when operating on natural gas. This is due to: high efficiency, which has already reached more than $60 \%$; low cost of construction and commissioning of a small period of operation, which is about 1.5-2 times lower than that for steam-turbine power units of supercritical pressure; low consumption of process water, which is three times lower per unit of power output than in the steam-turbine thermal power plants (TPP); less impact on the environment due to lower emissions [1] into the atmosphere and heat and water; greater maneuverability when compared to steam turbine plants.

Actual aspects is implementation of CCGT in the Russian TPP. This is due to the fact that for the generation of electricity in the CCGT is currently in use and $70 \%$ of natural gas in the next 30 years the proportion of combustible gas to generate electricity if and fall as a

\footnotetext{
"Corresponding author: gal@tpu.ru
} 
result of substitution of coal, it is quite immaterial. In this regard, actual is matter of finding ways to improve these units.

The most complete technological issues of the operate CCGT utilization type described in $[2,3]$.

In utilizing CCGT gas turbine cycle and steam turbine cycle are linked through the HRSB and if there is no additional fuel combustion, the CCGT efficiency is determined by the equation [3]

$$
\eta_{\mathrm{CCGT}}=\eta_{\mathrm{GTU}}+\left(1-\eta_{\mathrm{GTU}}\right) \eta_{\mathrm{HRSB}} \cdot \eta_{\mathrm{STU}}
$$

where: $\eta_{\mathrm{GTU}}$ - efficiency of the gas turbine unit (GTU); $\eta_{\text {Ку }}$ - efficiency of the HRSB; $\eta_{\mathrm{STU}}$ - efficiency of the steam turbine unit (STU).

As the basis for the work of CCGT are turbine and steam turbine cycles are the following ways to increase their efficiency:

1. Improvement of the cycle and equipment of the gas turbine unit;

2. Improving cycle and equipment of the steam turbine;

3. Improving the processes in the HRSB;

4. Reducing the cost of electricity for own needs.

Consider the most promising ways of increasing the efficiency of the CCGT in the basis of the analysis of foreign and Russian scientific literature.

\section{Improvement of the cycle and equipment of the gas turbine unit}

Electrical efficiency of the gas turbine unit is determined by the product of the thermal, electro-mechanical and internal relative efficiency. Internal relative and electro-mechanical efficiency are determined by manufacturing gas turbine perfection, the compressor and electric generator and is currently close to its maximum value. Therefore, the main way of improving the GTU is to increase the thermal efficiency.

In modern CCGT is used gas turbine Brayton cycle with inlet and outlet of heat at a constant pressure. The thermal efficiency of this cycle is determined by inlet and outlet temperatures of heat. The temperature of heat input is interconnected with inlet temperature and during its growth increases. The main way to increase the thermal efficiency is to increase the heat input temperature. The temperature of heat input is determined by the material from which made the combustion chamber and the gas turbine, as well as the way of their cooling. Currently reliably mastered heat input temperature is $1500{ }^{\circ} \mathrm{C}$, while powerful GTU in the company's General Electric, Siemens, Alstom received an electrical efficiency of GTU 40 [4, 5]. Experimental plants already operating successfully at $1600{ }^{\circ} \mathrm{C}$. Expected electrical efficiency of GTU up to $43 \%$, GTU are being developed at a temperature of $1700{ }^{\circ} \mathrm{C}$ heat input that will provide efficiency up to $45 \%$ [4].

For reliable modern cooling turbine components GTU operate with high excess air ratio, which leads to higher costs in the power the compressor.

Improving the efficiency of gas turbine technology was conducted mainly in the interests of the aviation industry and is to increase the initial temperature of the gases at the turbine inlet by cooling the gases washed by these parts of cyclic air GTU. Due to the complex control of water and vapor phase changes, and also because of the limited temperatures of the cooler suggested to excluded applying of water cooling of the turbine components. However, the cooling steam is developed and successfully applied by firms General Electric (GE) and Mitsubishi (MHI). At full cooling steam nozzle devices of the first stages of the gas turbine after the gas temperature are reduced by about $45{ }^{\circ} \mathrm{C}$, while air cooling temperature drops to $100-120^{\circ} \mathrm{C}$. If the temperature of the gas in front of the 
rotor blades is maintained the same as in the air-cooling, the temperature of the gases in the combustion chamber and nitrogen oxide emissions will be significantly less $[6,7]$.

At the steam cooling decreased air bleed from the compressor for cooling the blades GT, reduced load on the compressor. The heat which gets in GT steam, the steam turbine power increases.

As a result, the efficiency of combined cycle power plant can be increased to $2 \%$. At the same time applying cooling air required $[8,9]$.

\section{Improving cycle and equipment of the steam turbine}

Steam turbine unit operates based on Rankine cycle. The main ways of improving the steam turbine plant are: increase the initial parameters; reheating steam; regenerative heating of feed water [10]; lowering the temperature of heat removal in the condenser; improving the flow part of the turbine.

Currently, the design flow of the turbine is used 3D modeling, which allowed to bring the upper limit of efficiency [11].

The initial temperature of the cycle of the steam turbine plant is determined by the temperature at the outlet of the gas turbine, which, depending on the type of turbine is in the range $450-640{ }^{\circ} \mathrm{C}$. These conditions define the initial temperature of the steam at 420 $610^{\circ} \mathrm{C}$. Increasing the initial pressure has little effect on improving efficiency, therefore to reduce capital investments and increase agility CCGT applied pressure is not higher than 16 $\mathrm{MPa}$.

Intermediate superheat steam is mainly used for allowable moisture of steam at the outlet of the turbine.

The regenerative heating of feed water at CCGT does not increase efficiency, therefore does not apply.

The only way to increase the efficiency of the steam turbine plant is to lower the temperature of heat removal in the condenser, but the application of water-cooled condensers lower condensation temperature below $20{ }^{\circ} \mathrm{C}$ uneconomical. To address this shortcoming in the regions with low temperatures outside air is used air-cooled condenser (ACC), which allow at reduce winter heat removal the temperature to near $0{ }^{\circ} \mathrm{C}$ and below. But by using water as the working fluid the cycle it is possible to freeze and destruction of the condenser. Therefore, [12] suggested in a steam turbine installation to use the binary cycle, where the upper cycle of works on the water, and the bottom - organic Rankine cycle low boiling substance (LBS), which allows to reliably remove heat in the lower cycle at temperatures below $0{ }^{\circ} \mathrm{C}$. Conducted in [13] research on the ACC and CCGT on different LBS showed that in the winter time can be 2-3\% increase CCGT efficiency.

\section{Improving the processes in the HRSB}

HRSG is the connecting link between the gas turbine cycle and steam turbine cycle. In equation (1) can be seen that the efficiency of HRSB significantly affect the second part, which defines the role of the steam turbine plant CCGT efficiency. The efficiency of HRSB is defined input and outlet temperatures of the flue gases. Inlet temperature of the gas of the HRSB is determined by a gas turbine and within $450-640{ }^{\circ} \mathrm{C}$. To prevent condensation and corrosion metal gas path gases outlet from the HRSB temperature is maintained above $100{ }^{\circ} \mathrm{C}$. As a result, the efficiency of HRSB does not exceed $86 \%$. Therefore, mainly by increasing the efficiency of HRSB is used of the technology operate boilers with a decrease in gas temperature below the point of Russia and the condensation of water vapor from the flue gas. Therefore, mainly by increasing the efficiency of HRSB technology is the use of 
boilers with a decrease in gas temperature below the dew point and condensation of water vapor from the flue gas. As shown in [14] the use of this technology allows in the increase the efficiency of 10-12\% HRSB, resulting in 2-3\% increase CCGT efficiency. Thus obtained from gas condensate can be effectively used at thermal power plants. In addition at water heat recovery from the flue gases is captured a significant portion of pollutants, which reduces pollution.

\section{Reducing the cost of electricity for own needs}

The electricity consumption for its own needs at the CCGT account for 1.5-2.5\%, with the main share comprises the cost of pumping water electric pumps. By changing the electric pump turbine engine (GTE), you can reduce the cost of electricity for own needs by $0.5-1.5$ At the same time the heat of flue gas turbine engine can be useful in HRSB, which will increase the capacity and the efficiency of steam turbine plant.

\section{Conclusions}

1. The main ways of increasing the efficiency of GTU is to increase the initial temperature and decrease air flow for cooling. As a result in the foreseeable future GTU efficiency can reach $45-47 \%$.

2. The main ways of increasing the efficiency of steam turbine plant is to increase the initial temperature of the steam, which can only be achieved in the application of GTU with high inlet temperatures and heat removal, as well as reducing heat removal temperature as a result of the ACC and binary cycle with organic Rankine cycle in the lower stage. This will allow the winter to increase the CCPP the efficiency of by 2-3 $\%$.

3. In order to increase the efficiency of HRSB is necessary decrease exhaust gas temperature below the dew point, which will increase the efficiency of HRSB $10-12 \%$, and CCGT the efficiency of by $2-3 \%$.

4. Replacement of steam turbine plant electric pumps gas turbine engine can reduce the cost of electricity for own needs CCGT by $0.5-1.5 \%$.

The research was realized with financial support of Minobrnauki of Russia in framework of FTP "Research and development in prior direction of scientific-technological complex of Russia in 2014-2020 years”, unique R\&D identifier RFMEFI58114X0001.

\section{References}

1. D. Gvozdyakov, V. Gubin, S. Shvab, A. Tanishev, MATEC Web of Conferences 72, 01037 (2016)

2. R. Kehlofer, B. Rukes, F. Hannemann, F. Stirnimann, Combined-Cycle Gas \& Steam Turbine Power Plants (PennWell Corporation, Tulsa, 2009)

3. A.D. Trukhniy, Parogazovyye ustanovki elektrostantsiy (MEI, Moscow, 2013) [in Russia]

4. G.G. Olkhovskiy, Therm. Eng. 2, 10 (2013)

5. D. Robb, Turbomachinery Intern. 2, 24 (2011)

6. G.G. Olkhovsky, Therm. Eng. 7, 8 (2016)

7. S.C. Gulen, Gas Turbine World 44, 26 (2014)

8. S.C. Gulen, Gas Turbine World 44, 33 (2014) 
9. K. Savina, A. Abramovskih, V. Haymin, S. Lavrinenko, MATEC Web of Conferences 72, 01042 (2016)

10. K. Larionov, D. Gvozdjakov, A. Zenkov, V. Zaytsev, EPJ Web of Conferences 110, 01034 (2016)

11. V. F. Kasilov, The series of siemens SST-200 - SST-900 Siemens in Russia, Therm. Eng. 62, 240 (2015)

12. N. Galashov, Power Technology and Engineering 48, 458 (2015)

13. N. Galashov, S. Tsibulskiy, V. Gubin, T. Serova, MATEC Web of Conferences 37, 01021 (2015)

14. N. Galashov, S. Tsibulskiy, A. Kiselev, MATEC Web of Conferences 72, 01029 (2016) 